\title{
The physical, social and emotional aspects are the most affected in the quality of life of the patients with cervical dystonia
}

\author{
Os aspectos físicos, sociais e emocionais são os mais afetados na qualidade de vida dos \\ pacientes com distonia cervical
}

Roberta Weber Werle ${ }^{1}$, Sibele Yoko Mattozo Takeda ${ }^{2}$, Marise Bueno Zonta ${ }^{1}$, Ana Tereza

Bittencourt Guimarães ${ }^{3}$, Hélio Afonso Ghizoni Teive ${ }^{1}$

\begin{abstract}
Objective: Describe the functional, clinical and quality of life (QoL) profiles in patients with cervical dystonia (CD) with residual effect or without effect of botulinum toxin (BTX), as well as verify the existence of correlation between the level of motor impairment, pain and QoL. Method: Seventy patients were assessed through the Craniocervical dystonia questionnaire-24 (CDQ-24) and the Toronto Western Spasmodic Torticollis Rating Scale (TWSTRS). Results: The greater the disability, pain and severity of dystonia, the worse the QoL $(p<0.0001)$. Greater severity relates to greater disability $(p<0.0001)$. Pain was present in $84 \%$ of the sample, being source of disability in $41 \%$. The most frequent complaints were: difficulty in keeping up with professional and personal demands (74.3\%), feeling uneasy in public (72.9\%), hindered by pain (68.6\%), depressed, annoyed or bitter (47.1\%), lonely or isolated (32.9\%). Conclusion: The physical, social and emotional aspects are the most affected in the QoL of these patients.
\end{abstract}

Keywords: dystonia, quality of life, torticollis, neck pain.

RESUMO

Objetivo: Descrever o perfil funcional, clínico e de qualidade de vida (QV) de pacientes com distonia cervical (DC) com efeito residual ou sem efeito da toxina botulínica (BTX), bem como verificar a existência de correlação entre o nível de comprometimento motor, dor e QV. Método: Setenta pacientes foram avaliados através do Craniocervical dystonia questionnaire-24 (CDQ 24) e Toronto Western Spasmodic Torticollis Rating Scale (TWSTRS). Resultados: Quanto maior a incapacidade, dor e gravidade da distonia pior a QV ( $p<0,0001)$. A maior gravidade está relacionada à maior incapacidade $(p<0,0001)$. A dor esteve presente em $84 \%$ da amostra sendo fonte de incapacidade em 41\%. Dificuldade em manter-se com as demandas profissionais e pessoais (74,3\%), sentir-se desconfortável em público (72,9\%), prejudicado pela dor (68,6\%), deprimido, irritado ou amargurado (47,1\%), solitário ou isolado (32,9\%) foram as queixas mais frequentes. Conclusão: Os domínios físico, social e emocional são os mais prejudicados na QV desses pacientes.

Palavras-chave: distonia, qualidade de vida, torcicolo, cervicalgia.

Dystonia is a movement disorder characterized by sustained or intermittent muscle contractions causing abnormal, often repetitive, movements, postures, or both. Dystonic movements are typically patterned, twisting, and may be tremulous. Dystonia is often initiated or worsened by voluntary action and associated with overflow muscle activation ${ }^{1}$.

Among the various forms of dystonia, the most frequent in adults is the cervical dystonia (CD), a focal type that affects the muscles of the cervical region ${ }^{2}$.
This disorder is complex and its impact has been related to the reduction in quality of life (QoL) of the affected patients ${ }^{3}$.

Although different studies ${ }^{4,5,6}$ have evaluated the impact on the QoL of patients with cervical dystonia, few use a specific scale for the disease.

So, the objective of this study was to describe the functional, clinical and QoL profiles in patients with CD receiving follow-up treatment in the Movement Disorders Unit of the

'Setor de Distúrbios do Movimento, Serviço de Neurologia, Departamento de Medicina Interna, Hospital de Clínicas, Universidade Federal do Paraná, Curitiba PR, Brazil;

${ }^{2}$ Universidade Federal do Paraná, Curitiba PR, Brazil;

${ }^{3}$ Universidade Estadual do Oeste do Paraná, Cascavel PR, Brazil.

Correspondence: Roberta Weber Werle; Rua Dr Bozano, 711/203; 97015-001 Santa Maria RS, Brasil; E-mail: robertawwerle@hotmail.com

Conflict of interest: There is no conflict of interest to declare.

Received 04 November 2013; Received in final form 11 March 2014; Accepted 01 April 2014. 
Hospital de Clinicas of the Universidade Federal do Paraná, with residual effect or without effect of treatment with botulinum toxin (BTX). The study also aimed to verify the existence of correlation between the level of motor impairment, pain and QoL and analyze the impact of the severity of $\mathrm{CD}$ and of pain on activities of daily living and QoL.

\section{METHOD}

Seventy patients with CD, in a convenience sample, in follow-up in the reference units for treatment of dystonia of the Neurology Service of the Hospital de Clínicas of the Universidade Federal do Paraná were evaluated by the researcher and first author of this study from May 2012 to November 2012. The assessment protocol included collecting data of the clinical history in the medical record, an interview and application of the scales CDQ-24 and TWSTRS. The evaluations were performed on the day the patients would receive the application of BTX, before the procedure. The applications are made respecting the minimum interval of four months, according to the routine practice of this service.

The study began after approval from the Human Research Ethics Committee of the Hospital de Clínicas of the Universidade Federal do Paraná on May $2^{\text {nd }} 2012$, protocol number 27572, and all the patients that agreed to participate have signed the Informed Consent Form.

A road map was created to obtain the clinical history data and the following information was obtained from the medical record: age, gender, clinical presentation of $\mathrm{CD}$, spread of $\mathrm{CD}$ to other body parts and data concerning the early or late onset of the disease. For the classification of the time of onset of symptoms, ages below or equal to 26 were considered as early onset and ages over 26 were considered as late onset?

The patients were inquired, in an interview, about the occurrence of early retirement due to the disease, manifestation of headache and dystonic tremor, being the possible answers yes or no. The patients were also inquired about the occurrence of orthopedic and neurological complications and were requested to present computerized tomography exams and spine $\mathrm{x}$-rays in case they had any.

The CDQ-24, developed and validated in the University of Innsbruck, Austria, is the first specific instrument to assess the QoL in patients with craniocervical dystonia. This instrument addresses the perceptions and concerns of the patients and it can be used to assess the impact of the disease in areas not covered by the Short Form-36 Health Survey (SF-36) $)^{8,9}$.

Even as a generic measure of health status widely adopted to assess QoL ${ }^{8}$, the SF-36 has not been used in this study, since it has undergone a considerable amount of reliability tests and validity studies, proving to be impaired in patients with craniocervical dystonia?.

The 24 questions of the CDQ-24 are divided in five areas: stigma (6), emotional wellbeing (5), pain (3), activities of daily living (6) and family/social life (4). Each question has five possible answers, in which 0 (zero) is the best and 4 is the worst. The total score of the CDQ-24 ranges from 0 (best QoL) to 100 (worst QoL).

The TWSTRS was developed by Consky et al. ${ }^{10}$ and it is considered the gold standard in the classification of the severity of dystonia. The scale consists of three subscales designed to assess the motor aspects of $\mathrm{CD}$, measure the impact on the activities of daily living and gauge the pain caused by dystonia and its consequences on the lives of the affected individuals. The clinical presentation consists of four patterns: torticollis (head rotation in the axial plane), laterocollis (lateral head tilt in the coronal plane), retrocollis (head extension in the sagittal plane) and anterocollis (head flexion in the sagittal plane). The evaluation of the sensory tricks considers the type of relief (partial, complete or no benefit) experienced when it is used by the patients.

The total score ranges from 0 (best state) to 85 (worst state). The more severe the disease, the higher is the final score.

The study included patients diagnosed with $\mathrm{CD}$, aged 18 or over 18, in follow-up in the reference units for treatment of CD of the Hospital de Clínicas of the Universidade Federal do Paraná, having received BTX to treat the CD at least once in the year of 2012 and having had the last application at least 4 months before the day of the evaluation. Patients who presented, on their medical records, diagnoses of conditions with cognitive impairment that prevented the application of the questionnaires and the ones that missed the follow-up in the reference units or that refused to participate in the research were excluded from the study.

\section{Statistics}

For a sample of 70 patients with $\mathrm{CD}$, in a convenience sample, the level of significance (Type I error) established was 0.012 , beta (Type II error) of 0.012, generating an analytical power of 0.98 , with effect size of 0.5 . These calculations were performed in the program GPower 3.1.3 $3^{11}$.

The quantitative variables were demonstrated through median, minimum and maximum. The data obtained with the use of the CDQ-24 and the TWSTRS were analyzed by descriptive statistics for the characterization of the sample.

The correlation analyses were performed using Pearson's correlation coefficient $(\mathrm{r})$, testing significance by t-test correlation $(\alpha=0.05)$.

The composition of an explanatory model of the aspects regarding quality of life, disability and pain in patients with $\mathrm{CD}$, as well as the validation of the structural model were performed using Structural Equation Models and the AMOS software (v.19, SPSS Inc., Chicago, IL). 
Table 1. Relative and absolute frequencies of the types of clinical presentation of dystonia in the sample.

\begin{tabular}{lcc}
\hline & \multicolumn{2}{c}{ Frequency } \\
Clinical Presentation & Absolute & Relative \\
\hline 1 Type & 20 & \\
Torticollis & 6 & $28.5 \%$ \\
Laterocollis & 2 & $8.5 \%$ \\
Retrocollis & 1 & $1.8 \%$ \\
Anterocollis & & \\
2 Types & 25 & $35.7 \%$ \\
Torticollis + laterocollis & 7 & $10 \%$ \\
Torticollis + retrocollis & 3 & $4.2 \%$ \\
Anterocollis + laterocollis & 3 & $4.2 \%$ \\
Torticollis + anterocollis & & \\
3 Types & 3 & $4.2 \%$ \\
$\quad$ Torticollis + retrocollis + laterocollis & $3 \%$ \\
\hline
\end{tabular}

\section{RESULTS}

The median age of the evaluated patients was of 50 years old (39-65, first and third quartiles), varying between 21 and 79 years old, being 44 (63\%) women and $26(37 \%)$ men, in a ratio of 1.6:1. The median age of onset was 39 years old (21-54, first and third quartiles), varying between 0 and 76 years old.

Regarding the clinical presentation, $58.3 \%$ of patients presented more than one type of $\mathrm{CD}$ and the torticollis was the presentation more prevalent, being present in $56(80 \%)$ patients (Table 1).

The onset in adulthood (after 26 years old) was predominant in this sample, happening to $46(65.7 \%)$ patients.

The spread of dystonia to other body parts was observed in $21(30 \%)$ patients and the dystonic tremor in 50 (71.4\%).
In this sample, 28 (40\%) patients had orthopedic complications and the most frequent were scoliosis and cervical herniated disc. Regarding their work, the research showed that $20(28.6 \%)$ patients were, at the time of the assessment, in early retirement due to the disease and, when questioned, 38 (54.2\%) reported having headaches at least once a month after the diagnosis of CD.

The characterization of QoL through the scales stigma, emotional wellbeing, pain, activities of daily living and family/social life from CDQ-24 regarding the responses that showed higher frequency in the sample (always, often, severely, very severely) is shown on Table 2 .

Regarding the total score of the questionnaire, the median was 52 (39-66, first and third quartiles) points ranging between 13 and 90 points.

The duration of head deviation was reported as constant $(>75 \%$ of the time) by $26(37.1 \%)$ patients. Evaluating the occurrence of shoulder elevation/anterior displacement in these patients, it was found that 55 (78.6\%) had elevation.

The complete relief of the tremor and head deviation with the use of sensory tricks was reported by 45 (64.3\%) patients (Table 3 ).

Table 4 characterizes the presence of disability for work, activities of daily living, driving, reading, watching television and activities outside the home in the sample, according to the TWSTRS.

In the subscale pain of the TWSTRS, $11(15.7 \%)$ patients reported not feeling pain. Of the $59(84.3 \%)$ patients that reported feeling pain due to the disease, the median between the three gradients (worst pain, best pain and usual pain)

Table 2. Items of the subscales of the craniocervical dystonia questionnaire-24 that presented higher frequency of responses often, always, severely and very severely in the sample.

\begin{tabular}{|c|c|c|c|}
\hline \multirow{2}{*}{ CDQ-24 - Subscales } & \multirow{2}{*}{ Items } & \multicolumn{2}{|c|}{ Frequency } \\
\hline & & Absolute & Relative \\
\hline \multirow[t]{6}{*}{ Stigma } & Avoid places with many people & 44 & $62.9 \%$ \\
\hline & Felt uneasy in public & 51 & $72.9 \%$ \\
\hline & Need to conceal the disease & 35 & $50 \%$ \\
\hline & Concern with the reaction of other people & 36 & $51.4 \%$ \\
\hline & Unsure or tense with new people & 44 & $62.9 \%$ \\
\hline & Felt not to look so good & 36 & $51.4 \%$ \\
\hline \multirow[t]{3}{*}{ Emotional wellbeing } & Felt depressed & 33 & $47.1 \%$ \\
\hline & Felt annoyed or bitter & 33 & $47.1 \%$ \\
\hline & Felt sad or on the verge of tears & 31 & $44.3 \%$ \\
\hline \multirow[t]{3}{*}{ Pain } & Prevented from falling asleep by pain or a pulling sensation in the neck & 17 & $24.3 \%$ \\
\hline & Pain/a burning sensation in the face, head or neck region & 43 & $61.4 \%$ \\
\hline & Felt hindered by pain/a burning sensation in the face, head or neck region & 48 & $68.6 \%$ \\
\hline \multirow{3}{*}{ Activities of daily living } & Difficulty to do pleasant activities & 45 & $64.3 \%$ \\
\hline & Difficulty to keep up with the demands of work or personal life & 52 & $74.3 \%$ \\
\hline & Difficulty as a motorist or pedestrian & 40 & $57.1 \%$ \\
\hline \multirow{2}{*}{ Social/familiy life } & Felt isolated or lonely because of the dystonia & 23 & $32.9 \%$ \\
\hline & Problems with close friends or family due to the dystonia & 14 & $20 \%$ \\
\hline
\end{tabular}


Table 3. Efficacy of the sensory trick for relief of tremor and head deviation in the sample, according to the Toronto Western Spasmodic Torticollis Rating Scale severity subscale $(n=70)$

\begin{tabular}{lcc}
\hline \multirow{2}{*}{ Tricks } & \multicolumn{2}{c}{ Frequency } \\
& Absolute & Relative \\
\hline Complete relief & 45 & $64.3 \%$ \\
Partial relief & 13 & $18.6 \%$ \\
Little or no benefit from tricks & 12 & $17.1 \%$ \\
\hline
\end{tabular}

was 4.7 (3.7-6.2, first and third quartiles) ranging between 0 and 10 points.

The duration of pain in relation to the absolute number of patients is shown on Figure.

In this sample, considering the pain subscale of the TWSTRS, it was observed that $41 \%$ of patients have some sort of disability according to their levels of pain.

The median total score of the TWSTRS in this sample was 28.3 (21.2-36.4, first and third quartiles) points.

There was a relation between the QoL of the patients in this sample with the disability, severity and pain. Worse QoL was related to greater disability $(r=0.60 ; p<0.0001)$, greater severity of $\mathrm{CD}(\mathrm{r}=0.65 ; \mathrm{p}<0.0001)$ and greater pain felt by the patient $(\mathrm{r}=0.51 ; \mathrm{p}<0.0001)$. Greater disability in this sample was also related to greater severity of $\mathrm{CD}(\mathrm{r}=0.54$; $\mathrm{p}<0.0001$ ).

The impairment in the QoL of patients with CD can be observed by the fact that patients at some point feel they do not look so good ( $b=1.21 ; \mathrm{p}=0.002)$, present difficulties performing leisure activities $(b=0.92 ; p=0.011)$, feel hindered by pain ( $b=1.03 ; p=0.002)$, feel sad or on the verge of tears $(b=1.37 ; p<0.001)$, can't keep up with the work demands $(b=1.17 ; p=0.001)$ and present difficulties in locomotion, as a motorist and/or a pedestrian $(\mathrm{b}=1.11 ; \mathrm{p}=0.004)$.

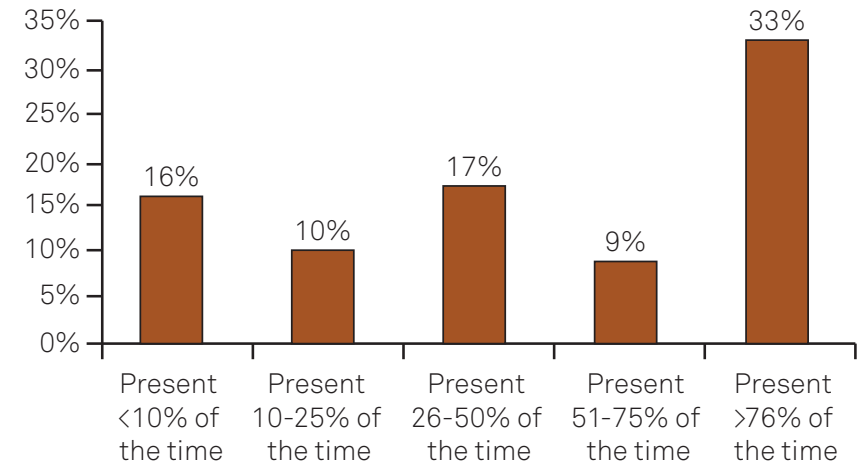

Figure. Representation of the duration of pain in the sample.

To define the association of the categorical variables of the instruments CDQ-24 and TWRTRS about quality of life and severity of CD patients, data modeling using structural equations was performed. The disability caused by dystonia was observed when performing activities of daily living $(b=0.637 ; p<0.001)$, reading $(b=0.775 ; p<0.001)$, watching television $(\mathrm{b}=0.882 ; \mathrm{p}<0.001)$ and at work $(\mathrm{b}=0.752 ; \mathrm{p}<0.001)$. There was a direct relationship between the worsening of QoL with the disability caused by pain $(b=1.06 ; \mathrm{p}=0.060)$.

\section{DISCUSSION}

This study evaluated patients with $\mathrm{CD}$ describing in details in which way the physical, emotional and social aspects are affected, compromising their QoL. In the evaluation, the patients had residual effect or no effect of treatment with BTX. The study of Fabiani et al. ${ }^{12}$ also performed in this service, designated 78.6 days as the average duration of the effects of BTX, providing the basis for the election of the interval of 4 months.

Table 4. Relative and absolute frequencies in the Toronto Western Spasmodic Torticollis Rating Scale disability subscale in the sample

\begin{tabular}{|c|c|c|c|}
\hline \multirow{3}{*}{ Work } & Disability Level & \multicolumn{2}{|c|}{$\begin{array}{c}\text { Frequency } \\
\text { AbsoluteRelative }\end{array}$} \\
\hline & $\begin{array}{c}\text { Normal work expectations with satisfactory performance at usual level of occupation but some } \\
\text { interference by torticollis. }\end{array}$ & 21 & \\
\hline & $\begin{array}{c}\text { Unable to engage in voluntary or gainfulemployment; still able to perform some domestic } \\
\text { responsibilities satisfactorily. }\end{array}$ & 16 & $22.9 \%$ \\
\hline \multirow[t]{2}{*}{$\begin{array}{l}\text { Activities of daily } \\
\text { living }\end{array}$} & Activities unlimited but some interference by torticollis. & 27 & $38.6 \%$ \\
\hline & $\begin{array}{c}\text { Most activities unlimited, selected activities very difficult and hampered but still possible using } \\
\text { simple tricks. }\end{array}$ & 10 & $14.3 \%$ \\
\hline Driving & No difficulty. & 49 & $70 \%$ \\
\hline \multirow[t]{2}{*}{ Reading } & Unlimited ability to read in normal seated position but bothered by torticollis & 25 & $35.7 \%$ \\
\hline & Unlimited ability to read in normal seated position but requires use of tricks to control torticollis. & 26 & $37.1 \%$ \\
\hline Watching television & $\begin{array}{l}\text { Unlimited ability to watch television in normal seated position but requires use of tricks to } \\
\text { control torticollis. }\end{array}$ & 19 & $27.1 \%$ \\
\hline $\begin{array}{l}\text { Activities Outside the } \\
\text { Home }\end{array}$ & Unlimited activities but bothered by torticollis. & 25 & $35.7 \%$ \\
\hline
\end{tabular}


Interference of $\mathrm{CD}$ to perform activities of daily living was noted; being pain a limiting factor associated, in this study, with both the disability as with the severity of dystonia. Signs of isolation, impaired social interaction and emotional limitation also point to the negative impact on the QoL of these patients.

In the study sample, 44 (63\%) patients were female and the median age of onset was 39 years old. The prevalence of $\mathrm{CD}$ in women has been addressed by various authors ${ }^{13,14,15}$ as well as the fact that the average age for the onset of dystonia is around 40 years old, confirming the findings in this study.

Patients with CD may present head deviations in only one plane or present complex movements of head and neck around several axes. In this study the combination of movements was observed in 41 (58.4\%) patients and the torticollis was the most prevalent presentation $(80 \%)$, data that also confirms the study of Salvia et al. ${ }^{16}$.

The onset age and spread are closely linked to the severity of the disease: when the disease starts in childhood/ youth, it usually progresses from focal to severe generalized dystonia, whereas the dystonia that begins after 26 years old generally affects craniocervical muscles and often remains localized or segmental, not progressing. In this study sample, 46 (65.7\%) patients had the onset of symptoms in adulthood justifying the little progression of dystonia observed only in $21(30 \%)$ patients ${ }^{17}$.

Pain is a limiting factor in quality of life ${ }^{3}$, being associated in this study to disability and severity of dystonia. The direct relationship between the worsening of QoL with the disability caused by pain was evident. Remarks like "unable to sleep due to pain or a pulling sensation in the neck", "pain or a burning sensation" and "hindered by pain or a burning sensation in the face, head or neck region" point to the impairment caused by pain in the QoL of these people.

In this study, $84.3 \%$ of the patients reported pain, in $32.8 \%$ pain lasted most of the day ( $>76 \%$ of the time) and $17 \%$ of the patients stated that pain is the major source of disability. According to Lowenstein and Aminoff ${ }^{18}$, the occurrence of pain in patients with CD increases from $21 \%$ in the initial assessment to $75 \%$ when the disease is at its worst stage. Pain has also been related to postural changes characteristic of $\mathrm{CD}$, such as elevation of one shoulder ${ }^{15}$. In this study, 55 (78.5\%) patients presented shoulder elevation/anterior displacement. In the literature review conducted by Konrad et al. ${ }^{19}$, the variation of orthopedic and neurological complications in patients with dystonia has been estimated at between 18 and $41.2 \%$, corroborating the present study in which $40 \%$ of patients had orthopedic complications.

Another common pain for patients with CD is the headache attributed to craniocervical dystonia, listed in the new classification of the International Headache Society (IHS) since $2004^{20}$. In this study, $38(54.2 \%)$ patients reported experiencing some kind of headache, similar to data found in the study of Barbanti et al. ${ }^{21}$, in which 45 (56\%) patients with craniocervical dystonia had headaches.

Among the patients evaluated in this study, $71.4 \%$ had head tremor and $64.3 \%$ use sensory tricks to perform some activities such as reading (37.1\%), watching television (27.1\%) in a seated position, similarly to the data of Pal et al. ${ }^{22}$ who found that $68.4 \%$ of the patients had head tremor and $60.2 \%$ used sensory tricks. Leis et al. ${ }^{23}$ described the sensory tricks as a clinical feature of patients with cervical dystonia and found that they were used by $70 \%$ of the patients.

A study of Zetterberg et al. ${ }^{24}$ evaluated the energy expended to perform the movements of the neck. In general, the movements performed by the patients with $\mathrm{CD}$ require more energy than the movements of the healthy individuals. The motor dysfunction in patients with CD seems to lead to excessive effort, beyond what is necessary to perform these tasks. This finding can explain the disability individuals with cervical dystonia present and thus the difficulty in manual work, reading, work demands, leisure activities, activities outside the home, watching television, activities of daily living and performing activities as a motorist/pedestrian, interfering directly in the QoL of these patients.

The impact of dystonia in the ability to work was also observed in this study, in which $20(28.6 \%)$ patients were in early retirement due to the disease. In the study of Martikainen et al. ${ }^{25}, 97$ (39\%) patients with cervical dystonia were retired at an average age of 48 years old.

Some studies have reported that patients with CD face a lifetime of chronic disability and associate the impairment of their QoL with factors that involve their physical and emotional health ${ }^{5,26}$. This study was able to list emotional problems linked to dystonia, such as the need to conceal the disease from other people, insecurity around new people, problems with friends and family members, fears regarding the disease and feeling often on the verge of tears, sad and annoyed.

The physical limitation in patients with $\mathrm{CD}$, i.e. the interference of dystonia in QoL and in the execution of activities, was described in this study that related the subscale disability of the TWSTRS and the CDQ-24. Pain would be a possible explanation for this interference. The other possibility is that these patients have a stigma associated with the emotional and social wellbeing affected, which induces them to limit their activities. This could also explain the isolating behavior towards the public observed in these patients. These factors discourage patients and lead to a negative impact on their QoL.

Page, Butler and Jahanshahi ${ }^{8}$ listed functional disability, the concept of body, the feeling of deformation, depression and the extent of dystonia as predictors of QoL. In this study, the influence of these factors on the QoL of the sample can be observed by the significant percentage of patients that 
reported difficulties in performing leisure activities, keeping up with work demands, difficulty to attend public places, being uneasy in public, having concerns with people's reaction towards the disease and isolation.

One of the limitations of the study was the period of data collection, with the patient without effect or with residual effect of BTX. The ideal would be the collection to be performed before and around 15 days after treatment with BTX (onset and peak of the effect) ${ }^{12}$, but due to the different provenances and low adherence, this idea was abandoned. Another factor that may be considered a limitation is targeting on $\mathrm{CD}$ patients, without comparing with patients without CD.
In conclusion, in this sample the torticollis and the presentation of more than one form of $\mathrm{CD}$ were prevalent. The functional profile was characterized by the presence of disability, with the work, daily life and outside the home activities impaired. Pain proved disabling and was related to worse QoL. Greater severity was related to greater disability and both were determining factors for worse QoL in this sample. The impact of CD may be observed through the frequent complaints such as "keeping up with professional and personal demands, feeling uneasy in public, impaired by pain, depressed, annoyed or bitter, lonely or isolated". The impairment in QoL was observed especially in the physical, social and emotional aspects.

\section{References}

1. Albanese A, Bhatia K, Bressman SB, et al. Phenomenology and classification of dystonia: a consensus update. Mov Disord 2013;28:863-873.

2. Claypool DW, Duane DD, Ilstrup DM, Melton LJ. Epidemiology and outcome of cervical dystonia (spasmodic torticollis) in Rochester, Minnesota. Mov Disord 1995;10:608-614.

3. Pekmezovic T, Svetel M, Ivanovic N, et al. Quality of life in patients with focal dystonia. Clin Neurol Neurosurg 2009;111:161-164.

4. Camfield L, Ben-Shlomo Y, Warner TT. Epidemiological study of dystonia in Europe Collaborative Group. Impact of cervical dystonia on quality of life. Mov Disord 2002;17:838-841.

5. Ben-Shlomo Y, Camfield I, Warner T, ESDE collaborative group. What are the determinants of quality of life in people with cervical dystonia? J Neurol Neurosurg Psychiatry 2002;72:608-614.

6. Müller J, Kemmler G, Wissel J, et al. The impact of blepharospasm and cervical dystonia on health-related quality of life and depression. J Neurol 2002;249:842-846.

7. Friedman J, Standaert DG. Dystonia and its disorders. Neurol Clin 2001;19:681-705.

8. Page D, Butler A, Jahanshahi M. Quality of life in focal, segmental, and generalized dystonia. Mov Disord 2007;22:341-347.

9. Müller J, Wissel J, Kemmler G, et al. Craniocervical dystonia questionnaire (CDQ-24): development and validation of a diseasespecific quality of life instrument. J Neurol Neurosurg Psychiatry 2004;75:749-753.

10. Consky ES, Basinki A, Belle L, Ranawaya R, Lang AE. The Toronto Western Spasmodic Torticollis Rating Scale (TWSTRS): assessment of validity and inter-rater reliability. Neurology 1990;40(Suppl1):S445-S445.

11. Faul F, Erdfelder E, Lang AG, Buchner A. Statistical power analyses using $G *$ Power 3.1: Tests for correlation and regression analyses. Behavior Research Methods 2009;41:1149-1160.

12. Fabiani G, Teive HAG, Germiniani F, Sá D, Werneck LC. Aspectos clínicos e terapêuticos em 135 pacientes com distonia. Arq Neuropsiquiatr 1999;57:610-614.

13. Bhidayasiri R, Kaewwilai L, Wannachai N, Brenden N, Truong DD, Devahastin R. Prevalence and diagnostic challenge of dystonia in
Thailand: a service-based study in a tertiary university referral centre. Parkinsonism Relat Disord 2011;17:15-19.

14. Defazio G, Abbruzzese G, Girlanda P, et al. Does sex influence age at onset in cranial-cervical and upper limb dystonia? J Neurol Neurosurg Psychiatry 2003;74:265-267.

15. Epidemiologic study of dystonia in Europe (ESDE) Collaborative Group. Sex-related influences on the frequency and age of onset of primary dystonia. Neurology 1999;53:1871-1873.

16. Salvia P, Champagne O, Feipel V, Rooze M, Beyl DZ. Clinical and goniometric evaluation of patients with spasmodic torticollis. Clin Biomech 2006;21:323-329.

17. Tarsy D, Simon DK. Dystonia. N Engl J Med 2006;355:818-829.

18. Lowenstein DH, Aminoff MJ. The clinical course of spasmodic torticollis. Neurology 1988;38:530-532.

19. Konrad C, Vollmer-Haase J, Anneken K, Knecht S. Orthopedic and neurological complications of cervical dystonia - review of the literature. Acta Neurol Scand 2004;109:369-373.

20. Headache Classification Committee of the International Headache Society. The International Classification of Headache Disorders. 2nd ed. Cephalalgia 2004;24:1-160.

21. Barbanti P, Fabbrini G, Pauletti C, Defazio G, Cruccu G, Berardelli A. Headache in cranial and cervical dystonia. Neurology 2005;64:1308-1309.

22. Pal PK, Samii A, Schulzer M, Mak E, Tsui JKC. Head tremor in cervical dystonia. Can J Neurol Sci 2000;27:137-142.

23. Leis AA, Dimitrijevic MR, Delapasse JS, Sharkey PC. Modification of cervical dystonia by selective sensory stimulation. J Neurol Sci 1992;110:79-89.

24. Zetterberg L, Halvorsen K, Färnstrand C, Lundström E, Lindmark B, Aquilonius SM. Objective assessment of cervical dystonia: a pilot study. Acta Neurol Scand 2005;112:248-253.

25. Martikainen KK, Luukkaala TH, Marttila RJ. Working capacity and cervical dystonia. Parkinsonism Relat Disord 2010;16:215-217.

26. Gudex CM, Hawthorne MR, Duffey P. Effect of dystonia and botulinum toxin treatment on health-related quality of life. Mov Disord 1998;13:941-946. 